Dr. Carlos Charlín.

\title{
El programa espiritual de un universitario
}

(Coníerencia de Exfensión Universitaria dada en Concepciōn el 24 de Diciembre de 1923)

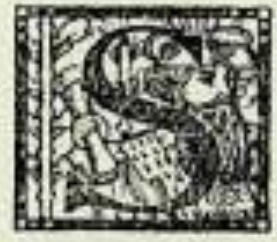

EÑORAS, señor Presidente, señores Prolesores de la Universidad, Señores.

siento un vivo orgullo, no por cierto sin una mezcla de emoción, al hablar en esta Universidad, que desde lejos he admirado y con vivo inferés he seguido en sus primeros pasos.

La he admirado por lo que es ya, por lo que promete ser y tambiên por su significado profundamente consolador: revela una altura de miras, una visión del porvenir. un altruísmo, un ambiente social, en fin, digno de un país muy culto.

Concepción. esta reina del Sur, es la reina fluvial de Bio-Bio. y como reina tiene una corona; pero a ella le faltaba el diamante que foda corona tiene: la Universidad se lo ha dado al engastar en metal el brillante de la chispa intelectual.

Es para mi muy honroso venir a colaborar, aunque sea sólo un instante, en una obra que enaltece a esta ciudad y dignifica a este pais. La tarea que emprendo es temeraria, lo sé: pero haré todo lo que esté de mi parte para no quedar en la demanda.

$\mathrm{Y}$ entro en materia.

El espiritu de un hombre maduro liene ciertas caracteristicas inmutables; no está sujeto a variaciones; ha tomado, si pudiéramos decir. ciertos pliegues imborrables: ha adquirido cierta fijeza en la manera de observar, de sentir, de juzgar: se ha cristalizado en un tipo determinado.

pero esa cristalización espiritual ha venido preparándose lenta y sigilosamente. y la forma que toma el cristal depende en gran parte, - no lo olvidemos. - de los primeros años de vida libre y consciente: es decir. de esa época vecina a la veintena, que coincide justamente con la vida universitaria. 
No digo que todo dependa de ella. porque siempre lo fundamental es la materia prima. son las cualidades innatas, buenas o malas, propias de cada individuo.

Lo que es plomo no será transformado en oro por la educación, nijpor la instrucción, ni por ningún medio extraño. Todos conocen el caso de Nerón, que. rodeado desde su más tierna infancia de los filósofos, de los sabios más eminentes de su época. murió como habia nacido: nació una fierecilla' y murió una fiera, desgarrando el pecho que lo había amamantado, degollando al maestro que lo había enseñado.

Pero es preciso decir también que el oro no trabajado permanece en el estado de vil metal, mezclado a la tosca piedra y no utilizado por nadie.

La educación, la instrucción, tienen esa misión santa: descubrir en la tierra humana la veta que todos poseen, más o menos rica, de metal más o menos precioso: que existe en el fondo de nuestra alma; y. descubierta ella, explotarla. y el metal extraido refinarlo, pulirlo y convertirlo, si posible fuera, en una filigrana, en una alhaja.

Pues bien, es preciso que los jóvenes sepan que ese trabajo... de selección. de purificación, de valorización, no lo hace la escuela: que para esa verdadera ciencia intima no hay cátedra en esta Universidad, ni en ninguna otra del mundo: que ese trabajo especialisimo de valorización espiritual sólo lo puede hacer cada uno lentamente en su fuero interno.

La formación del intelecto y del alma debe iniciarse temprano, en plena juventud, especialmente durante la vida universitaria.

Yo quiero indicar a los jóvenes de esta Universidad algunas líneas generales del programa de formación espiritual, indicarles cómo pueden ir preparándose para que, cuando llegue la edad adulta, la época de fijación de la personalidad. de cristalización, poscan un cristal limpido y de mil reflejos.

\section{Jóvenes,}

desde el primer paso os debo decir que si realmente queréis alcanzar altura espiritual y. por ende. moral, si queréis ser de veras intelectuales en toda la fuerza que este concepto tiene, como parece indicarlo el que sigáis estudios universitarios, debéis imponeros ciertas normas para el futuro.

Debéis considerar la vida con un criterio distinto al del industrial, al del comerciante, al del hombre de negocios.

El dinero, para vosotros, futuros abogados, médicos, ingenieros, efc., no debe ser lo principal; no es ni puede ser vuestra suprema ambición.

Aquéllos de vosotros que sigan después en silencio guiando su barca por la estrella del peso, ésos conseguirán talvez la fortuna, pero no conseguirăn nunca ni la altura moral, ni la altura espiritual de un intelectual de verdad. Podrán ser envidiados, pero nó respetados, y quién sabe si ya viejos, serán, a pesar de su dinero. despreciados por la juventud futura.

Si queréis sinceramente emprender una obra de perfeccionamiento mental y moral, es preciso quitar del camino este prejuicio del dinero, que desorienta a la mayor parte de los hombres. que aplasta y ahoga las mejores ilusiones y tron- 
cha el destino de muchos mortales. Debéis trabajar sin ser guiados por esa brújula: debéis trabajar por placer, y nó por interés.

El dinero debe ser un medio: no debe ser un fin. Hay que mirarlo como merece, sin respeto, como a sirviente, nó como a patrón, y en cuanto se puede. hay que despedirlo como se despide a un mal criado.

Os voy a decir cómo lo trataba don Vicente Reyes, el ilustre patricio, orgullo de toda una generación, quien, sin lugar a dudas, vivió rodeado del mayor prestigio con que haya vivido un chileno.

Don Vicente, antes de llegar a la senectud, encontrándose aún en plena fuerza y poseedor de una mediana fortuna, fruto de su trabajo, resolvió tirar una raya sobre el factor económico: la renta de que disfrutaba era suficiente para subvenir a sus modestas necesidades, y adquirir más dinero ya no tenia razón de ser para él. Resolvió trabajar, trabajar siempre, pero nó para él, sino para los demás.

Una tarde se presentó a su bufete un caballero, heredero de una de las principales fortunas de Chile, y le pidió que hiciera la partición de propiedades urbanas y rurales, valores bancarios, efc., ascendentes a cerca de treinta millones de pesos, lo que significaba un honorario de varios centenares de miles. Don Vicente le contestó que estaba retirado de la vida activa profesional y que ya no se interesaba por esta clase de trabajos. Como insistiera el heredero y tratara de convencerlo, aduciendo que la partición no iba a presentar dificultad alguna y que la farnilia estaba dispuesta a pagar principescamente el servicio, don Vicente replicó: Señor, si la familia Rotschild me trajera sobre una bandeja de plata sus bienes para que los partiera. le devolvería la bandeja con un millón de gracias..

Pocas semanas después se le ofreció la partición de los bienes del señor Abello, que dejaba cuantiosas sumas para obras de beneficencia. Don Vicente Reyes aceptó con la condición de no recibir emolumento alguno.

Para este patricio, el dinero era un objeto de lujo. de ostentación, y no tenía mayor interés que una perla o un brillante, que habria rehusado llevar en un anillo o en su corbata.

Me perdonaréis que me explaye acerca de este punto: pero tal insistencia ha sido intencionada. Vivimos en Chile, país nuevo, una de las primeras elapas de la civilización, la elapa económica: la pobreza o, por lo menos, la modestia reinante hacen aparecer el dinero como el factor principal o talvez el más interesante de la vida. Comprendo que domine ese criterio allá en la ciudad; es así, porque debe ser así; pero en la Universidad, aquí, debemos sentir aires más puros y debemos esforzarnos todos por crear una atmósfera idealista.

Este desinterés, este renunciamiento económico de que os hablo y que os parecerá doloroso, lo practican el magistrado, el pedagogo, el soldado, y lo debe realizar el universitario de capitán a paje, de profesor a estudiante. Empero. notad que no pido para vosotros la pobreza franciscana: nó. Deseo sólo ese término medio económico, el más propicio para la labor espiritual: esa cdorada medianía de Horacio, tan fácil de alcanzar en nuestra tierra cuando se trabaja.

$\mathrm{Si}$ os dedicáis al estudio, a este estudio desinteresado, no vais a ser Cre- 
sos ni Petronios: pero vais a ser mucho más: vais a ser Quijotes en un mundo poblado de Sanchos. El mundo espiritual es el bien sumo, dice un filósolo romano: si lo posees. comienzas a ser compañero de los dioses. Llegar a ese punto del sendero es seguro y fácil, y la Naturaleza te ha provisto de todo lo necesario para alcanzarlo. No será el dinero lo que te haga compañero de los dioses. ni tampoco la reputación extendida por los pueblos: tampoco la multitud de criados que lleven tu litera por caminos y ciudades: tampoco la belleza y la fuerza del cuerpo. sujetas a la vejez. Necesario es, pues, buscar algo de lo que no se compra y a lo que nada se oponga ¿Qué será esto? El espíritu; y este espiritu puede encontrarse en un caballero romano. en un liberto y en un esclavo... y Séneca agrega una frase revolucionaria que, repetida después de treinta generaciones, levantaría de seguro una polvareda... ¿Qué es un caballero romano, un liberto o un esclavo? Palabras, nombres nacidos de la ambición y de la injusticias.

Supongamos cortados los lazos que mantenian vuestro espiritu atado a la tierra, a la materia, a la vulgaridad, a la platifud: prometed ser desinteresados y habréis roto la cadena. y vuestro espiritu ya libre podrá volar hacia altas regiones.

Ahora, ¿cómo alcanzar esa actividad plena de la inteligencia que, con el transcurso de los años será rica madurez intelectual, el más preciado adorno que puede ostentar un hombre? Sometiéndose desde temprano, desde luego, a una disciplina de trabajo. imponiéndose cierlas normas en la vida. trazándose un programa. El lema que debe inspirar ese programa es el perfeccionamiento constante. el enriquecimiento no suspendido de vuestra intelectualidad.

Os debe animar un ansia de saber y debéis permanecer eternamente inclinados sobre .esa fuente milagrosa que nunca se altera.. La fuente inagotable del saber está a vuestro alcance: son los libros y es la vida.

Los libros os dirán las verdades que estudiando han conquistado vuestros mayores: la vida os entregará las verdades que seáis capaces de arrebatarle.

\section{La lectura}

Es preciso que la lectura se convierta para vosotros en una necesidad y llegue a iniciarse como un acto reflejo. Establecida la costumbre. dejaos llevar: I'habitude est une seconde menagère, dice Sully Prudhomme; es una segunda dueña de casa que manda dictatorialmente. Sin esfuerzo, ella irá día a día proveyendo vuestra despensa, os irá enriqueciendo.

Pero debéis vigilarla, debéis dirigirla suavemente, porque suele convertirse en urraca que llena la casa de cuanto encuentra a su paso; y si la dejáis. tendréis conocimientos disparatados y desordenados. y vuestro hogar hará la impresión de una casa de consignación y no de una residencia culta, elegante, refinada.

Hay que saber leer y lo que debe leerse. Se leerá diariamente: se hará 
voto de lectura; pero hay que leer moderadamente: dos horas al dia bastan. Una hora en veinte años puede convertiros en sabios.

Porque hay que dejarse tiempo para observar y pensar: las lecturas excesivas ahogan el espíritu, lo intoxican, hacen desaparecer la personalidad, y el pensamiento se convierte en un pálido y frío reflejo del pensamiento extraño. Se pasa a ser algo así como una colonia de potencia extranjera, y la independencia siempre se defiende como sagrado bien, aunque lo que se defiende sea pobre.

Establecida la costumbre de la lectura consciente e inteligente, habréis adquirido uno de los medios que con los años os armarán caballeros de la idea.

\section{Lecturas profesionales}

Se leen con un espíritu distinto un libro de enseñanza y una revista.

El primero, el libro didáctico, se aborda en estado de asimilación. tratando de retener cuanto de importante traen sus páginas, en completo abandono espiritual, en el estado de alma del niño de colegio. Se lee como un creyente lee un libro de le.

La revista, por el contrario, se abre con el espiritu alerta, pronto a la discusión. y cuanto se lee debe pasar por el tamiz de la crítica. Ni debe discutirse lo que los maestros afirman como indiscutible. ni debe aceptarse como cierto lo que permanece aún en el terreno de la hipótesis.

¿Qué leerá el joven profesional? En primer lugar deben llegar a sus manos los buenos libros que se publican y una o dos revistas de la especialidad a que se dedique. Nada nuevo de cuanto ocurra en ese dominio puede ignorar.

\section{Lecturas no profesionales}

Pero el joven que limite sus lecturas a su especialidad, que cultive sólo ese campo, consiente en una limitación de su intelecto que lo deforma: será un intelectual unilateral: atravesará la vida con anteojeras, y. como el caballo que arrastra el coche a través del bello paisaje, sólo verá el camino.

El profesional tendrá el espíritu abierto a todos los conocimientos humanos: cientificos, literarios, filosóficos, arfísticos, y sus lecturas versarán sobre temas generales y no sólo sobre temas profesionales.

Pero aqui cabe también una nueva clasificación.

\section{Leeturas de pasatiempo}

Apropiadas para época de vacaciones. Hay lecturas ligeras, como, por ejemplo. las novelas. Se dan vuelta las páginas sin pensar: es una lectura de entretenimiento. Esta lectura no deja ningún provecho: es un pasatiempo de poco más valor que el juego del naipe. del dominó o de las damas. No son recomendables: son inútiles. cuando no perjudiciales, y nos parecen más dignas de una vida espiritualmente ocio- 
sa que de la de un estudioso. Éste, cuando abre un libro, debe hacerlo con el sano propósito de obtener algún provecho, de proveer su despensa, siempre pobre.

No me refiero aqui a las novelas de fondo, de tesis, o que encierran un verdadero valor literario, como las de Balzac. Anatole France, Bourget. Tolstoy. D'Annunzio, etc., o de los grandes novelistas españoles, que forman el gusto artistico y cumplen asi el lema de vuestro programa: el enriquecimiento constante de vuestro intelecto.

Preferible a la novela es el libro de historia.

La novela es una historia artificial y lalsa de la vida; la historia es una novela vivida por seres semejantes a nosotros: es la exposición de crisis sociales y politicas acaecidas; es la novela del mundo, del cual nosolros también somos protagonistas. pero en época distinta.

Ninguna novela más apasionante que la Revolución Francesa. En ese cataclismo, por la brutal ruptura del equilibrio social, aparece suelta en la calle, en la asamblea, en el hogar, la bestia humana, que en todos nosotros existe y que ignoramos. porque dormita en la subconsciencia.

¿Qué decir de la epopeya napoleónica. de la historia de ese superhombre, tan superior y distinto a los demás hombres, que parecia un slobo viviendo en medio de un rebaño de ovejas. según la expresión del historiador?

Abrid la historia en cualquier página: aquí tenéis la novela sangrienta de las Repúblicas italianas. la novela feroz de la Inquisición. la novela teatral de Gustavo Adolfo de Suecia, la novela lúgubre de Felipe II. la novela pura como cristal de roca de Franklin...

iY qué escritores encontrâis para daros a conocer semejantes trozos de vida: a Macaulay, a Taine, a Cantú, a Michelet, etc., y. entre los modernos, a Ferrero!

Si os queréis entretener instruyéndoos, no tenéis sino la dificultad de escoger. Porque la historia os va también a instruir, ya que al mostraros la vida tal cual ha sido, os indica también cuál es. El mundo, cuanto más cambia, tanto más igual es a sí mismo.

La conmoción rusa de principios del siglo $\mathrm{XX}$ es la repetición, paso a paso, de la conmoción francesa de fines del siglo XVIII, el Fascismo, el Directorio español. son lenómenos parecidos observados muchas veces en el transcurso del tiempo: son los pretorianos de la antigua Roma, son los genizaros de Constantinopla adueñándose del poder cuando el César es débil e inepto.

$\mathrm{El}$ discurso que pronunció Mussolini en Montecitorio, en la Cámara de Diputados italiana. después de su golpe de Estado de Octubre de 1922, es una nueva edición del discurso pronunciado por Cronwell tres siglos antes en la Cámara de los Comunes. Asi habla la fuerza en todos los tiempos cuando se dirige a la debilidad, a la pusilaminidad, al miedo. Otras veces no necesita hablar. Uno de los Luises de Francia penefró al Parlamento después de una partida de caza, de sombrero puesto. con bota alta, calzado de espuelas, y lo disolvió con un movimiento de su huasca.

El pasado nos ilumina el presente.

Os decia que en la Revolución Francesa apareció a la luz del día la fiera humana; se asoma ella siempre en épocas anormales, cuando las pasiones excitadas 
soplan en huracán y hacen perder el self-control, es decir, el dominio de lo consciente sobre lo subconsciente.

En la última revuelta universitaria. los estudiantes que tomaron parte en la asonada de la clase de Fisiología y amenazaron de muerte a los fieles alumnos de mi querido profesor Muhm, los que vejaron y ultrajaron a este maestro, Bayardo sin miedo y sin tacha. honra de nuestra Escuela ésos habian perdido el auto-control y se encontraban a merced de su fiera.

El maestro se cruzó de brazos, los miró y los compadeció, y después... los perdonó.

De gran interés son también los libros de sociologia, de economía politica. de crítica literaria o artística. de viajes, etc.: pero. doblo la página, porque esto me arrastraría muy lejos de mi tema.

\section{Lecturas de fondo}

Literatura y Filosolia. Me refiero aquí a los clásicos, que posiblemente han despertado poco entusiasmo en vosotros... Es que no sabéis leerlos.

Abris el Quijote con el espiritu con que abris una novela. Profundo error. Los clásicos se deben leer muy despacio y reflexionando. Es licor que se bebe paladeándolo.

Esos príncipes del espiritu han escrito después de meditar, y nosotros, humildes siervos, debemos leerlos como ellos escribieron y rehacer, si nos fuera posible. la meditación que ellos hicieron.

Se lee, pues, para pensar.

El libro es una ayuda, un estimulante, un iniciador, pero nó una cadena (1).

Vivimos en el obscuro fondo del valle; el genio nos da la mano, y el pensar al unísono con él nos eleva a las cimas que él habita, nos acostumbra a los aires de las alturas, y cuando lo dejamos y volvemos a hundirnos en la media luz de nuestra medianía intelectual, nos queda como un resplandor de la alta montaña. Los genios son nuestros amigos, nos enseñan a pensar, a bien pensar: y esto no es sólo un deleite. Uno de ellos ha dicho: Bien penser: voilà le principe de la morale, (2). Si. aprender a bien pensar, he aquí el fundamento de toda moral.

Recuerdo que una tarde fui a ver a don Julio Zegers. Encontré al bello anciano. terminada su Frugal comida, leyendo; me mostró unas obras de Voltaire, de Lord Byron, y no recuerdo qué otras que estaban sobre su mesa, y me dijo: AAqui tenéis a mis amigos, a mis nobles amigos», y con una fina sonrisa, agregó: cy pensar que algunos caballeros del Club de la Unión creen honrarme con su amistad... No conocen el linaje de mis relaciones.

Si, haced como don Julio Zegers; buscad amigos entre los genios.

Si, es conveniente familiarizarse con tres o cuatro grandes pensadores y consultarlos, leerlos con regularidad, diariamente: un cuarto de hora de esta lectura basta.

(1) Sertillanges.

(2) Pascal. 
Os aconsejaria que formaráis al lado de vuestra pequeña biblioteca profesional, una colección de quince o veinte libros escogidos, literarios, filosóficos.

Sería difícil prever y calcular la acción benéfica que puede ejercer sobre una vida la influencia constante de un alma selecla, de un espiritu superior.

\section{El arte}

Después de haberos hablado de la lectura, quisiera detenerme en el arte: pero el tiempo no me lo permite.

Os diré sólo que si los grandes pensadores enseñan a pensar, los grandes artistas enseñan a sentir honda, pura y bellamente.

\section{La observación, la meditación}

La lectura, hemos visto, tiene por objeto distraer, llenar noblemente un descanso, enseñar o hacer pensar cuando se oye la voz de los grandes pensadores.

Pero. si la lectura no debe ocupar más de una o dos horas de la jornada. ¿significa esto que cuando el intelectual haya terminado su trabajo. deba silenciar su cerebro y entregarse a una existencia vegetativa?

Nó: este tiempo desocupado, en que no lee y no trabaja, es un tiempo precioso. es el tiempo en que se encuentra él solo consigo mismo, en que el pensamiento libre está en las mejores condiciones para claborar una obra personal.

El paseo. la marcha, el reposo del hogar, son instantes de reflexión, de conlesión intima, de auto-juicio: en las tierras del futuro, se trazan los caminos que se han de recorrer. se maduran las resoluciones que mañana han de tomarse.

Empero, esta contemplación interior está medida, fiscalizada, porque es fácil que se convierta en vicio y se deslice hasta el anonadamiento físico del nirvana hindú y del sosiego andaluz. Más importante y más interesante es la contemplación del mundo exterior.

Es el momento de leer el libro más cautivador de cuantos se han escrito y se escribirán: el libro de la vida.

Para leerlo. no basta mirar: hay que ver con los ojos de la inteligencia; hay que observar las cosas y los hombres, y meditar.

Todo despierta interés. porque en todo existe el misterio. Las cosas inertes tienen también su vida: mirad una flor, y muy luego advertiréis en esa pequeñez un mundo que no sospechabais y que no comprendéis.

De las cosas corrientes hay que elevarse a las ideas generales. Que la vista de un desamparado os haga pensar en la desigualdad de los hombres, en la injusticia social, y. también, en la triste e ineludible necesidad de que asi sea; soportaremos de mejor manera a los poderosos pensando que los mendigos nos soportan, ha dicho Schiller. Que la hilera de camas de un hospital no signifique, para un estudiante de medicina, sólo una serie de casos clínicos, sino que aparezca como una manifestación de la pobreza vergonzante a que se puede llegar, del dolor al cual se llega fatalmente. 
Un cielo estrellado en una noche plácida de verano deja insensible al iletrado. pero conmueve al pensador, que siente la grandiosidad del cosmos. la pequeñez del hombre, y su alma que vaga entre el infinito y la nada. Después de semejante contemplación, un inspirado borroneó estas contadas palabras: Le silence de ces espaces infinis m effraye.... (1).

Si. el verdadero intelectual encuentra en el más ligero impulso del exterior la ocasión de un movimiento sin fin que lo llevará a tanta mayor altura cuanto más poderosas sean las alas de su espiritu. El sabio pasea por todos los tiempos y por sobre todos los caminos una mente madura para las adquisiciones que el vulgo desperdicia.

Tener siempre el pensamiento a la expectativa: he aqui el secreto. Si no sabéis mirar asi, no seréis sino unos seres vulgares.

Aprended también a escuchar, y escuchad con atención al más pobre, al más burdo. Un sinnúmero de verdades circulan en los discursos más simples: un chuaso. es a ratos mucho más sabio que un filósofo.

Mirando y escuchando, aprenderéis a pensar.

En todo hay inteligencia: sólo el pobre de espiritu proyecta sobre todos los muros la sombra de su frente obtusa (2).

Ahora, observad a los hombres que os rodean; tratad de hacer de cada uno un bosquejo psicológico, y os sentiréis maravillados ante la infinita diversidad espiritual, diversidad tan infinita como la de las cosas materiales. Seria tema de meditación nunca terminada considerar la complegidad de los caracteres humanos.

Este presenta cualidades sobresalientes y defectos incomprensibles; este otro. al contrario. goza de un equilibrio aparente de sus facultades: piensa como Sócrates, habla como un oráculo, y, no obstante, procede a veces como un desequilibrado: aquél es de una rigidez y simpleza psicológicas tales, que hace la impresión de una figura egipcia, y aquel otro, en fin. es un enigma que en vano trataréis de descilrar.

Y al sorprender tanta diversidad junto a tanta imperfección. dudáis de vosotros mismos y perdonáis para ser perdonados.

Si observáis a los hombres, aprenderéis a ser ecuánimes; si os encerráis en vuestro gabinete, os formaréis un criterio inquisidor, atravesaréis la vida sin conocerla y llegaréis al término de vuestro viaje desorientados y destrozado el corazón.

El hombre observador, por el contrario. llega a la ancianidad sonriente: cuanto acontece, comprende; cuanto ve, disculpa. El doctor Roberto Aguirre, decano de la Facultad de Medicina, se complace en recordar una frase de su padre, don Joaquin Aguirre: El que quiera mula sin maña, que ande a pies. Yo quiero que sepáis desde luego que fodas las mulas tienen mañas y todos los hombres, graves defectos, y si queréis ser ayudados. tomad a los hombres como son y no como ojalá fuesen.

IQué interesante es también observar el móvil de los hombres! Este obedece sólo al dinero: aquél a ambición más noble, ha hecho de la filantropía su vida: éste,

(1) Pascal.

(2) Sertillanges. 
como la enredadera. sube asiéndose al robusto roble: este otro franquea sólo todas las efapas a golpes de esfuerzo, y. en fin, aquél, en plena juventud, recoge el velamen de su barco y se entrega a la corriente.

Se asiste, cuando se mira y se ve, a una lucha silenciosa, constante, que dura lo que dura la vida: lucha del hombre contra el hombre, del hombre contra la nam turaleza, del hombre contra el destino. Se asiste a un drama magnifico: el drama humano.

De esta excursión por el mundo material y espiritual, se vuelve enriquecido de experiencia, de equilibrio. de justicia: se vuelve más sabio en la ciencia que es la coronación de todas las ciencias: la filosolia: se vuelve más rico en bondad, que es la suprema filosolia.

Porque todos somos filósofos; cual más, cual menos; consciente o inconscientemente.

El silencio que sigue al trabajo. la ociosidad que separa dos lecturas, no son, pues, para el intelectual, una ociosidad vacia: no es el silencio de la nada del necio: es un silencio vivido, preñado de ideas, gracias a la contemplación del mundo exterior y a la reflexión. A este silencio debe de referirse el árabe cuando dice: La palabra es de plata, pero el silencio es de oro.

$Y$ las múltiples observaciones recogidas en estas constantes excursiones forman un rico bolin, un capital gracias al cual nacen, con la meditación, las ideas personales, propias, carne de la carne, no leidas en el libro, no dictadas por el vecino, que permiten pensar de una manera original, que imprimen un distintivo a la personalidad. Llevo en mi cerebro mi trono imperial., exclama Schiller con entusiasmo.

Se pasa de ser una cosa a ser alguien, a ser hombre, un hombre completo. Toute notre dignité consiste en la pensées, concluye fríamente Pascal.

Debéis ambicionar ser alguien, y lo seréis si tenéis vida interior.

Os he indicado los dos senderos que conducen a esta meseta luminosa, a ese supremo desiderátum del hombre inteligente: la lectura que os instruirá y os enseñará a pensar. la observación que os hará pensar.

Pero el intelectual no puede contentarse con ser un expectador mudo de la pieza a que asiste.

Limitarse a esto, sería hacer obra harto incompleta e inútil para la comunidad. Después de haber hecho suyo el mundo exterior, el pensador debe devolver lo recibido; marcado con su sello, debe exteriorizarlo.

\section{La palabra}

Ya en posesión de cierto bagaje de conocimientos y de experiencia. el intelectual debe transmitirlos a los dernás. debe hablar, debe escribir, debe enseñar a sus semejantes lo que sabe, debe tender la mano al que no sabe. como el Buen samaritano tendió la mano al herido del camino.

$\mathrm{El}$ que ignora, si no es un herido, es un inválido, es un ciego espiritual.

$\mathrm{El}$ intelectual debe comunicar sus ideas personales, sus observaciones propias 
y sus reflexiones, a sus compañeros, a sus amigos, sobre todo a sus jóvenes amigos.

-Todo quiero transmitirtelo, escribe Séneca a su amigo Lúcilo, porque no gozo en aprender algo, sino para enseñarlo a los demás. Si se me ofreciese la sabiduria a condición de tenerla oculta. la rechazaría.

Es necesario acostumbrarse a expresar su pensamiento en forma clara y concisa: mucho hay en esto de hábito y ejercicio. Debe escribirse lo más temprano posible: al principio se escribe mal; luego después se escribe mejor. La vergüenza, el pudor. el exceso de amor propio, cierran muchas bocas y paralizan muchas manos. Debéis combatir esa timidez.

No busquéis el adorno: escribid sencillamente, tal cual sale de vuestra pluma. La naturalidad, la espontaneidad, es la cualidad más preciada de un estilista.

Hablad sencillamente, sin retórica, contando las palabras como si fueran libras esterlinas. Hay que hablar poco: lo muy preciso. Vosotros sabéis que la mercancía se valoriza tanto más cuanto menos abundante es.

Hay que hablar poco, y la palabra ha de ser la expresión matemática de la idea. Esta, hemos visto, nace en el silencio. D'Annunzio admira en Beethoven sus maravillosos silencios: la melodía se interrumpe. sobreviene un silencio que se adivina cargado de armonias y de pensamientos, y luego después, la melodia continúa.

\section{El trabajo}

Por las razones de que hemos hablado, la lectura, la observación. la meditación, no son sino momentos preparatorios de la acción.

-Il faut se separer de la foule pour penser, s'y confondre pour agire, ha escrito Lamartine.

La acción es lo efectivo. lo real, lo que justifica vuestro paso por este mundo. En la acción vais a realizar lo que habéis aprendido, lo que habéis pensado. En la acción vais a construir.

El trabajo es el acto trascendental. Entrad a la acción con entusiasmo. con brios, con vehemencia.

Hundios en el trabajo con fruición. No entréis al escritorio, a la oficina, al taller, reloj en mano. pensando en la vuelta, porque entonces no os daréis por entero al trabajo, no daréis toda vuestra personalidad, y todo lo que hagáis será mediocre. Desde que os ponéis al trabajo, no os pertenecéis: sois esclavos de la acción.

Trabajad sin mediros, os repito: y entonces saltaréis todos los obstáculos, venceréis todas las dificultades. llegaréis alli adonde queráis llegar.

Nadie os podrá detener: talvez sea más fácil detener al río que cuesta abajo va hacia el mar, que sujetar al hombre resuelto que camina cuesta arriba. hacia las cumbres.

Acallaréis las criticas, ahogaréis las risas, el sarcasmo,-esa espada de los débiles, de los impotentes-, aplastaréis a los envidiosos y forzaréis el aplauso de vuestros enemigos. 
Se murmura, se dice que sois incompetentes: se contesta trabajando: que sois torpes: se contesta trabajando: que sois malos hombres: se contesta trabajando para los demás sin medirse.

El trabajo es un arma invencible, irresistible. . No conozco ninguna otra que permita en la vida ser vencedor por completo, sin remordimiento; no conozco ninguna otra que permita llegar a la cúspide con nobleza.

Pero esta arma formidable lo es sólo si es mancjada con constancia, con paciencia, con persistencia. Si sois unos trabajadores intermitentes, quedaréis rezagados en el camino.

Escuchemos a Pasteur, el hijo del obrero, que llegó con trabajo y constancia a ser deificado en vida: Travaillez; une fois que l'on est au travail, on ne peut plus vivre sans lui. D'ailleurs, c'est de là que depend tout dans le monde.

- C'est par un travail assidu, sans autre don particulier que celui de la persé vérence dans l' effort. joint peut être à l'attrait de tout ce qui est grand et beau. que i'ai trouvé le succés dans mes recherches.

He copiado estos pensamientos y los he clavado en una de las salas de mi clinica, a fin de que los jóvenes que alli concurren los lleven siempre clavados en la frente, y a fin. también. de que quien los copió no los olvide.

\section{El Éxito}

Si sois trabajadores, tened confianza en el porvenir, sed optimistas, risueñamente, ingenuamente optimistas.

La recompensa vendrá; exisle una justicia inmanente que aletea invisible en el espacio y cual dorada mariposa, espera la oportunidad de posarse sobre vuestras cabezas. Sabed esperar; dadle tiempo al tiempo.

El tiempo es el soberano comprendedor. Tened confianza en él: hunde lo que la casualidad - el nacimiento, la fortuna.... - ha elevado, y levanta de la obscuridad lo que debe alzarse y lo que merece la plena luz.

Voy a terminar dándoos un talismán. la llave con que podréis abrir la caja misteriosa del éxito, es decir. de la felicidad: que os dará holgura económica. bienestar espiritual, que os rodeará de prestigio, que os hará atravesar la vida entre caras sonrientes.

Os vay a indicar el excitante que mantendrá vuestra voluntad y vuestros músculos en tensión constante y que os permitirá hacer prodigios.

Existe en el hombre un resorte que pone en movimiento todo el mecanismo humano: existe una palanca que puede levantar un mundo y que ha creado mundos. Todos tenemos dos pasiones que no son quizá sino una. que ocultamos con rubor. porque ellas no son santos, no son de noble origen; pero que son estimables porque permiten realizar cosas nobles.

Hacer el bien, ser buenos, ser trabajadores, estas santas intenciones no bastan para mover a los hombres, que son hombres, y nó santos. "L homme n'est ni ange ni bête, et le malheur veut que qui veut faire l'ange fait la bête."

(1) Pascol. 
Si, el hombre, cuando quiere hacerse el santo. se convierte en bestia.

Esa pasión que mueve los actos humanos es el amor propio, la ambición. No temo decíroslo: sed ambiciosos; tened amor propio: tratad de ser los primeros. Pero los primeros, usando armas caballerosas.

Y. aunque no lo seáis. Iqué importal Habréis sido lo más que podiais ser: habréis hecho rendir vuestro patrimonio cuanto podia; después, podéis morir contentos.

$\mathrm{El}$ amor propio y la ambición, lo repito. mueven a los hombres, y me atrevo a hacer esta confesión, amparado por dos sombras ilustres.

Os vioy a dar primero la opinión de un genial gran señor que vivió en la corle del Rey Sol y que, por ese motivo, conoció a cuanto de más valor tuvo Francia durante el periodo más brillante de su historia. El duque de La Rochefoucault, ya viejo, retirado a sus tierras, antes de morir, nos dejó como legado sus terribles - Maximes, terribles de verdad y de franqueza. En ellas encontramos esta frase lapidaria: La virtud no iría muy lejos si no marchara apoyada del brazo del amor propio.:

Y ahora os diré lo que escribió otro genial pensador que vivió en la misma época. pero encerrado en un convento, en Port Royal. entre devolas, dedicado a martirizar su cuerpo para salvar su alma. Pascal escribe: -El amor propio está tan profundamente anclado en el corazón del hombre, que un soldado, un cocinero, un sirviente, se admiran a si mismos y quieren tener sus admiradores, y los filósofos tambièn quieren tenerlos. Y los que escriben contra tal vicio quieren tener la gloria de haber escrito bien, y los que lo leen quieren tener la gloria de haberlo leido, y yo, que escribo esto, talvez tenga también ese pueril deseo...

-Somos tan vanos, que la estimación de cinco o seis personas que nos rodean nos entretiene y nos contenta. El agrado de la reputación. de la gloria, es tan grande, que cualquiera que sea el precio qne se pague por ella, aun el de la muerte. siempre se la desea., Y por fin, este último saetazo: "morimos alegremente, siempre que se hable de ello.

Dascal ha comprendido tan bien estas pasiones porque este hombre santo, este espíritu genial, era un ambicioso y veia horrorizado en el fondo de su alma su inconmensurable amor propio.

Es un vicio innato e incurable. Transformad ese vicio en virtud, obligándolo a que haga de vuestra existencia una vida buena, bella y útil. 